\title{
Expediency of ATO in heavy rail: A survey for the Dutch Railways
}

\author{
M. Akbari ${ }^{1, *}, B$. Hoogewoonink ${ }^{2}, B$. Godziejewsk ${ }^{3}$, and $M$. Rajabalinejad ${ }^{4}$ \\ ${ }^{1}$ Master student, (University of Twente, ME, the Netherlands) \\ ${ }^{2}$ Consultant Railway Signalling and Safety, (Mott MacDonald, the Netherlands) \\ ${ }^{3}$ Senior Rail Manager, (Mott MacDonald, the Netherlands) \\ ${ }^{4}$ Assistant Professor, (University of Twente, ME, the Netherlands)
}

\begin{abstract}
Automatic train operation (ATO) is a relatively new trend in heavy rail. While technical specifications define system and function requirements, implementation and adoption of ATO requires a business case. In this research we have developed a framework which could indicate if a corridor is suitable for automatic operation or not. We have approached this challenge by using product development methods such as QFD (Quality Function Deployment) and methods developed specifically for this study. The results indicate that ATO could influence performance, time to market and costs with respect to manual operation. The influence depends on the characteristics of a corridor, corridor segmenting as well as the operational procedures. The positive influence of ATO, considering the current state of the Dutch railways, could be limited and there may be additional challenges.
\end{abstract}

\section{Abbreviations}

\begin{tabular}{|l|l|}
\hline ABBREVIATION & FULL FORM \\
\hline AoE & ATO over ETCS \\
\hline ARCC & Automated Rail Cargo Consortium \\
\hline ATO & Automatic Train Operation \\
\hline DMI & Driver Machine Interface \\
\hline EEIG & European Economic Interest Grouping \\
\hline ERA & European Union Agency for Railways \\
\hline ERTMS & European Railway Traffic Management System \\
\hline ETCS & European Train Control System \\
\hline GoA & Grade of Automation \\
\hline IEC & International Electrotechnical Commission \\
\hline JU & Joint Undertaking \\
\hline KPI & Key Performance Indicators \\
\hline QFD & Quality Function Deployment \\
\hline SPAD & Signal Passed At Danger \\
\hline
\end{tabular}

\footnotetext{
${ }^{*}$ Corresponding author: maryam.akbari@alstomgroup.com
} 


\section{Introduction}

Autonomous and automatic operation are the new trends in land transportation. Around 25 cities in the world have driverless metro systems and self-driving cars are expected soon. This trend did not find its way to heavy rail until recently. In the late 2017 , the first fully autonomous freight train started operation in a mining railway line in Australia.

This project along with the deployment of ERTMS have perhaps encouraged heavy rail undertakings to consider ATO. Within the developments of Shift2rail, now more demonstrators are being planned and there are a few ATO related projects (e.g. X2Rail, ARCC) [1]. In addition, ERA's interface and system specifications for an interoperable ATO over ETCS (GoA 2) operation are expected to be released soon.

However, implementing ATO on a rail corridor requires a business case. Corridors with special characteristics could be more suitable for ATO as benefits become significant while there could be corridors which benefits of ATO are limited. Consequently, it appears that a framework which can aid in the decision-making process is necessary. The objective of this research is to develop a tool which can be used in early phases of decision making. The tool is expected to determine the expediency of automatic operation for rail corridors in the Netherlands.

In this paper the methodology to develop and validate a decision-making tool is defined. This tool can be used to determine a business case for implementing ATO. The case studies were done by applying the tool to several rail corridors in the Netherlands. The conclusion and recommendations for future work were drawn based on study results.

\section{ATO over ETCS}

AoE is a concept in which ATO drives the train while a safety critical system (ETCS) is in place and protecting the train from hazards. ETCS is viewed a solution to implement an affordable and interoperable ATO in the heavy rail. The projects done by EEIG and Shift2Rail JU have contributed to better understanding the challenges related to ATO and have support elaboration of requirements specifications. The existing specifications for AoE are applicable for ETCS levels 1,2 and 3.

\subsection{ETCS}

ETCS is an interoperable train control system promoted by the European Commission. ETCS Level 2, which will be applied in the Netherlands, is based on cab signalling and continuous track to train data transmission. It provides an inherently safe operational environment for the movement of trains throughout the railway network [2].

\subsection{ATO}

ATO is a non-safety critical system which performs all or part of the tasks assigned to the train driver. The tasks performed by ATO depend on the GoA. IEC has defined 4 grades of automation [3]. This is further detailed in Table 1. 
Table 1. Share of tasks between the train driver and the System

\begin{tabular}{lcccc} 
Basic functions of train operation & GoA 1 & GoA 2 & GoA 3 & GoA 4 \\
\hline Ensure safe movement of train & ETCS & ETCS & ETCS & ETCS \\
\hline Drive train & D & S & S & S \\
Supervise passenger transfer & D/A & D/ A & A & S \\
Operate a train & D & D & A & S \\
Ensure detection and management of & D & D & A & S \\
emergency situations & & & &
\end{tabular}

\subsection{Current AoE development}

Only a few ATO over ETCS projects in heavy rail have been executed around the world. These projects, as shown in Table 2 .

Table 2. ATO over ETCS Deployment in the World

\begin{tabular}{lcccc}
\hline \multicolumn{1}{c}{ Parameter } & China Intercity & Thameslink & $\begin{array}{c}\text { Toluca - } \\
\text { Mexico City }\end{array}$ & Iron ore train \\
\hline GoA level & 2 & 2 & 2 & 4 \\
ATP & Eq. to ETCS & ETCS L 2 & ETCS L2 & ETCS L2 \\
\hline
\end{tabular}

\subsection{Other ATO developments}

Although ATO over ETCS is most promising development, however various railway undertakings and infrastructure managers have and are considering ATO over their legacy ATP systems. The slow deployment of ETCS has motivated these organizations to look for solutions to integrate automation within their legacy ATO systems. Example of such developments are:

1. France, remote cab for freight corridors,

2. Germany, remote cab for freight corridors,

3. The Netherlands, GoA 2 on passenger corridors,

4. Austria, GoA 4 for freight corridors,

5. Russia, GoA 2 for passenger corridor,

6. Russia, remote cab for freight corridor,

\section{Methodology}

In this section, the main assumptions and approach for developing the framework are briefly discussed.

\subsection{Assumptions}

This research focuses on ATO over ETCS Level 2. As the target train control system for Dutch Railways is expected to be ETCS Level 2 [4].

It is assumed that in GoA 3 and 4 there are obstacle detectors installed on-board. Furthermore, the performance of these devices is assumed to be at least similar to a human driver by the time the ERA specifications for GoA 3 and 4 are released. 


\subsection{Approach}

The approach taken to develop the framework is summarized in Figure 1 and explained below.

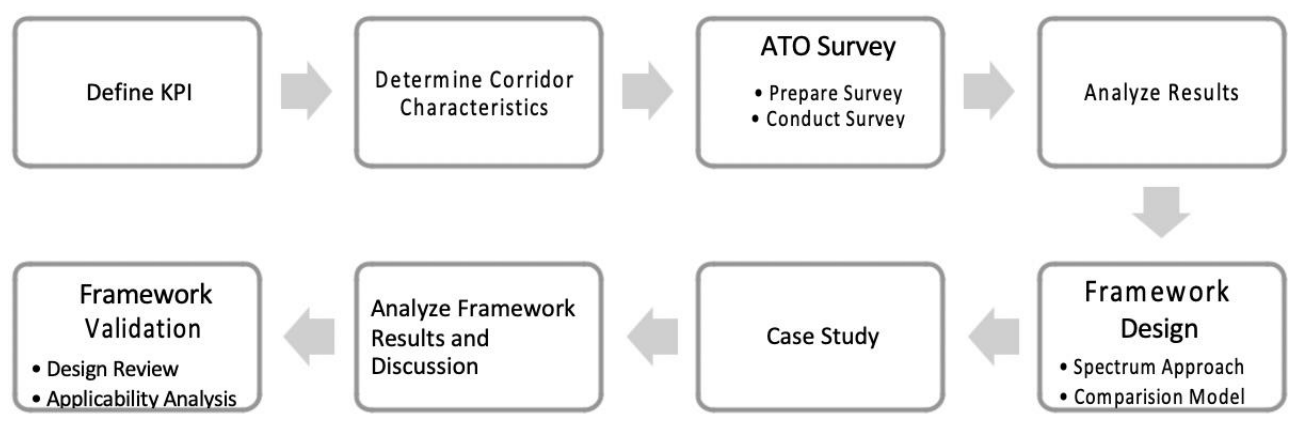

Figure. 1. Summary of Methodology

The initial step to develop the decision-making framework was to define KPIs which can support the business case. Considering the model developed by Hayes and Wheelwright [5], several KPIs along with their contributing indicators which best represented performance, time to market and financial aspects were defined.

Then 16 corridor characteristics which could influence the defined KPIs, were identified. The relation between the KPIs and corridor characteristics as well as the impact of different GoA on the KPIs were determined by Dutch railway experts using a survey. In the next step, the survey was prepared, conducted and results were analysed. The survey results were used to form a multicriteria analysis to design the decision-making framework.

The ATO decision-making framework was then applied to several rail corridors in the Netherlands and results were analyzed and discussed.

Finally, in order to validate the framework two methods were developed. The first validation method included review meetings. As the final step, the framework was applied to two currently automated urban rail systems.

\section{Defining KPIs}

KPIs are set of quantifiable measures that organizations use to measure their performance against business objectives. As "performance" is viewed differently within every organization, different measures are used by them.

However, the KPIs defined for this research are typical in the railway environment and often used by railway undertakings and infrastructure managers.

\subsection{Performance}

The performance parameters generally include those parameters which are part of the concessions and deviation from agreed values results in penalties. These KPIs are:

\subsubsection{Safety}

Safety is defined as the freedom from conditions that can cause death, injury, occupational illness, damage to or loss of equipment or property, or damage to the environment [6]. The 
European parliament and of the council have defined several indicators to measure safety in the railways in Directive (EU) 2016/798 [7]. These indicators include:

- No. of SPADs,

- No. of over-speeding,

- No. of collisions with object / person near the track,

- No. of collisions with object / person on the platform,

- No. of collisions with road vehicles at level crossings,

\subsubsection{Punctuality}

Punctuality is the property of an event occurring "on time". The main contributing indicator for punctuality in heavy rail is variation from running time.

\subsubsection{Capacity of a corridor}

"Capacity is a measure of the ability to move a specific amount of traffic over a defined rail line with a given set of resources under a specific service plan" [8]. Therefore, capacity of a corridor can be measured through the difference between theoretical and practical capacity. The former refers to the maximum number of trains which can run over a route in a strictly perfect, mathematically generated environment. The latter represents the practical number of trains which can be moved considering a reasonable level of reliability [8].

\subsubsection{QoS (Quality of Service)}

Ride comfort is a common measure to determine the quality of service. For this study, vibration is selected as a representative parameter. Braking and acceleration contribute to the felt vibration and could be influenced by automation. Therefore, the contributing indicator for QoS is decided as the percentage of inconvenient braking / accelerating.

\subsubsection{Reputation}

Reputation, by definition of the Cambridge dictionary, is the opinion that people in general have about someone or something. Innovation is one of the contributing factors to reputation, [9]. For this research innovation is measured by percentage of automated driving tasks.

\subsection{Time to market}

TTM refers to the time from which a company initially conceives a product or service idea to the point when the actual product or service is accessible in the market. In the railways, the time to market could includes flexibility as it deals with the train service becoming available to the passengers.

\subsubsection{Flexibility}

Flexibility could be referred to making changes. A flexible system is a system in which changes are relatively easy to make [10].

Scheduling a train driver is one of the most time taking and complex tasks for the railway undertaking. There is little flexibility in this process and changes are difficult to make due to the numerous variables and constraints. Example of the variables and constraints include 
qualifications, legislations, shift hours, etc. [11]. In order to measure flexibility, the number of variables to plan a driver for train operation is used.

\subsection{Financial aspects}

Financial and economic aspects are related to the life cycle costs which includes the investment, operation and maintenance costs.

\subsubsection{Railway operational expenses}

For this study, the operational expenses are related to the operation of the train in the railway. In the railways, the operation charges are mainly due to the energy consumption and the costs associated with the driver / conductor. Accordingly, the following could represent railway operating expenses:

5.1 Energy usage per train per km

5.2 Staff expenses per train

\subsubsection{ATO Investment expenses}

Capital costs are fixed, one-time expenses for purchasing equipment. For this study, the capital costs are expressed as the costs to deploy an on-board and trackside ATO equipment.

\subsubsection{Railway maintenance expenses}

Railway infrastructure and rolling stock require frequent maintenance in order to keep them in good condition, ensure smooth running of the trains and avoid hazardous situations. The maintenance costs could be divided between and measured with the expenses related to the infrastructure manager and the railway undertaking

\section{Determining corridor characteristics}

This section includes the corridor characteristics assumed to have an influence on the KPIs discussed in the previous section. These corridor characteristics were determined during brainstorming sessions with Dutch railway experts as well studying available literature, as shown in Table 3.

Table 3. Form Determined Corridor Characteristics

No. Corridor Characteristic No. Corridor Characteristic

1 Average Distance between stations $9 \quad \begin{aligned} & \text { No. of Level Crossings (LX) for Road } \\ & \text { Vehicles }\end{aligned}$

$2 \quad$ Number of Stations

10 Available Infrastructure Capacity

3 Maximum Line speed

11 Infrastructure Condition 
No. Corridor Characteristic

$4 \quad$ No. Junctions

$5 \quad$ Suicide history

6 Corridor Length

7 Track Segregation

$8 \quad$ Average Track Adhesion Conditions
No.

Corridor Characteristic

12 Traffic Heterogeneity

13 Current No. of trains

14 Train Type

15 Number of Passengers

\section{ATO survey}

In this section, the process to prepare, conduct and analyze the results of the survey are explained.

\subsection{Preparation of the ATO survey}

Selecting a template format and a ranking system were required to perform the survey. The survey template was taken from the relation matrix of the QFD, which is a structured approach to define customer needs.

Two qualitative ranking steps were defined. The choice of a qualitative over quantitative approach was done to have less inconsistent data and to assure that the survey could be completed in a realistic timeframe. The first ranking step, used to indicate the relation between the KPIs and the corridor characteristics, was a binary or $0-1$. Experts could state if there is a link between corridor characteristics and a KPI or not. The second one would indicate how KPIs in different GoA would vary in relation to GoA 1. Table 4 presents the choices given to the experts for the second step:

Table 4. Second ranking step

\begin{tabular}{l|c}
\multicolumn{1}{c}{ Ranking } & Symbol \\
\hline Strong increase $(>50 \%)$ & $\pi \lambda$ \\
\hline Weak increase $(<50 \%)$ & $\boldsymbol{\lambda}$ \\
\hline No Change & $\rightarrow$ \\
\hline Unknown & $\boldsymbol{?}$ \\
\hline Weak decrease $(<50 \%)$ & $\boldsymbol{K}$ \\
\hline Strong decrease $(>50 \%)$ & $\boldsymbol{K} \boldsymbol{K}$ \\
\hline
\end{tabular}

The survey which given to the participants can be found in Appendix A.

\subsection{Conducting the ATO survey}

15 candidates for conducting the survey were selected from different organisations to get representative and comprehensive results. Experts from infrastructure managers, railway 
undertakings, signaling consultants, university scholars and governments representatives were asked to participate. Experts were also asked to indicate the KPIs which are applicable in a future business case.

The list of experts whom were asked to participate, their expertise and related organizations can be found in Appendix B.

\subsection{Integrating survey results}

An integration criterion was needed to combine and integrate the different viewpoints experts could have. The following criterion was used to merge the answers:

"A marking in the relation matrix is decided for if at least half of the participants have marked it."

\section{ATO survey results}

After the survey answers were collected and integrated, they were reviewed. The answers provided by the experts were similar in most cases. Dissimilar answers were given for the impact of automation on safety and maintenance KPIs. In this section, the results of the survey are detailed and discussed.

\subsection{Business case KPIs}

As mentioned in 7.2, experts were asked to specify which KPIs should be taken into consideration for a business case. Among the initially defined KPIs, experts selected 7 KPIs, as shown in Table 5. Some KPIs were linked to corridor characteristics, while others were independent from the characteristics of a corridor. This is shown in the last column of Table 5.

Table 5. Business Case KPIs

\begin{tabular}{|c|c|c|c|c|c|}
\hline \multirow{2}{*}{ Category } & \multirow{2}{*}{ KPI\& Contributing Indicators } & \multicolumn{3}{|c|}{ GoA } & \multirow{2}{*}{ Dependency } \\
\hline & & 2 & 3 & 4 & \\
\hline \multirow{6}{*}{ Performance } & 1. Punctuality & & & & \\
\hline & 1.1 Variation from running time & $y$ & ע & $\searrow$ & $\begin{array}{l}\text { Corridor } \\
\text { dependant }\end{array}$ \\
\hline & 2. Capacity of a Corridor & & & & \\
\hline & $\begin{array}{l}2.1 \text { Difference between theoretical and } \\
\text { practical capacity }\end{array}$ & $y$ & ע & $\searrow$ & $\begin{array}{l}\text { Corridor } \\
\text { dependant }\end{array}$ \\
\hline & 3. Reputation & & & & \\
\hline & $\begin{array}{l}3.1 \text { Percentage of automated driving } \\
\text { tasks }\end{array}$ & $\pi$ & ス & ス & $\begin{array}{c}\text { Corridor } \\
\text { independent }\end{array}$ \\
\hline \multirow{4}{*}{$\begin{array}{l}\text { Time to } \\
\text { Market }\end{array}$} & 4 Flexibility & & & & \\
\hline & $\begin{array}{l}\text { 4.1 Number of variables to plan a } \\
\text { driver for train operation }\end{array}$ & $\rightarrow$ & ע & ע & $\begin{array}{l}\text { Corridor } \\
\text { Independent }\end{array}$ \\
\hline & 5 Railway Operational Expenses & & & & \\
\hline & 5.1 Energy usage per train per km & $y$ & ע & y & $\begin{array}{l}\text { Corridor } \\
\text { dependant }\end{array}$ \\
\hline
\end{tabular}




\begin{tabular}{|c|c|c|c|c|c|}
\hline \multirow{2}{*}{ Category } & \multirow{2}{*}{ KPI\& Contributing Indicators } & \multicolumn{3}{|c|}{ GoA } & \multirow{2}{*}{ Dependency } \\
\hline & & 2 & 3 & 4 & \\
\hline \multirow{7}{*}{$\begin{array}{l}\text { Financial } \\
\text { Aspects }\end{array}$} & 5.2 Staff expenses per train & $\rightarrow$ & 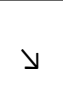 & $\begin{array}{l}\searrow \\
\searrow\end{array}$ & $\begin{array}{c}\text { Corridor } \\
\text { independent }\end{array}$ \\
\hline & 6 ATO Investment Expenses & & & & \\
\hline & 6.1 On-board ATO & $\lambda$ & $\begin{array}{l}\lambda \\
\pi\end{array}$ & $\begin{array}{l}\pi \\
\pi\end{array}$ & $\begin{array}{l}\text { Corridor } \\
\text { dependant }\end{array}$ \\
\hline & 6.2 Trackside ATO & $\pi$ & $\pi \pi$ & $\pi ス$ & $\begin{array}{c}\text { Corridor } \\
\text { dependant }\end{array}$ \\
\hline & 7 Railway Maintenance Expenses & & & & \\
\hline & $\begin{array}{l}\text { 7.1 Expenses for Infrastructure } \\
\text { Manager }\end{array}$ & $\pi$ & $\lambda$ & $\pi$ & $\begin{array}{c}\text { Corridor } \\
\text { dependant }\end{array}$ \\
\hline & 7.2 Expenses for Railway Undertaking & $\lambda$ & $\lambda$ & $\lambda$ & $\begin{array}{l}\text { Corridor } \\
\text { dependant }\end{array}$ \\
\hline
\end{tabular}

\subsection{Influencing corridor characteristics}

Among the 16 corridor characteristics, only 8 have an influence on KPIs indicated in Table

5. These corridor characteristics are:

1. Number of stations

2. Track segregation

3. Theoretical number of trains (per hour)

4. Current number of trains (per hour)

5. Corridor length

6. Type of service (regional, intercity, freight, mixed)

7. Maintenance frequency of infrastructure

8. Total number of rollingstock

\section{Framework design}

The survey results indicate that there is a link between the corridor characteristics and the KPIs. ATO could impact the KPIs due to these links. Therefore, the state of the KPIs in GoA 1 (for a corridor) should first be determined. Then it could be decided if automation can have an impact on the KPIs or not. This is done by a method specifically developed for this research, the "Spectrum approach", as explained below.

\subsection{Spectrum approach}

The spectrum approach uses a binary logic to decide if a contributing indicator of a KPI is likely to impact the KPI or not. Every contributing indicator has its own spectrum. The spectrum depends on the corridor characteristics which have a link to the contributing indicator of a KPI. This is further explained with an example.

"Variation from dwell time" is a contributing indicator for punctuality. A variation happens when passenger boarding, and de-boarding does not take place according to the timetable. Conductors usually wait for all the passengers to de-board and board from a train, then lock the doors and allow the train to depart. The delays on the passenger rail corridors in the Netherlands were reviewed and variations were found to be common on busy stations. Examples of such stations include Amsterdam Central and Utrecht Central. 
In GoA 4, the conductor is replaced with a system. The system no longer waits for the passengers, and starts the train as planned in the timetable. Therefore, the variation from dwell time is expected to decrease. However, this impact would only be noticeable at busy stations, where the variation from dwell time was originally more probable.

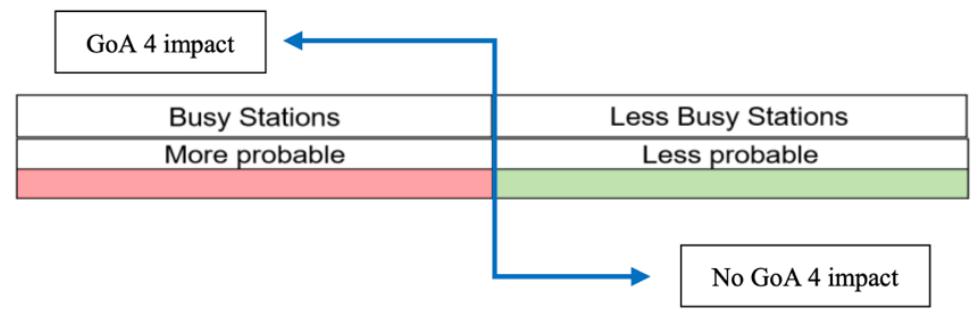

Figure. 2. Example of Spectrum Approach

\subsection{Comparison model}

In order to decide on the expediency of ATO, a quantitative cost - benefit analysis was done. The cost - benefit parameters were taken from the KPIs shown in Table 3. 4 possible states could result from the cost - benefit analysis:

- High costs - low benefits

- High costs - high benefits

- Low costs - low benefits

- Low costs - high benefits

These states could be translated to "Suitable for ATO", "ATO not recommended" and "Unknown / Undecided". For every GoA, a separate basis for comparison was defined.

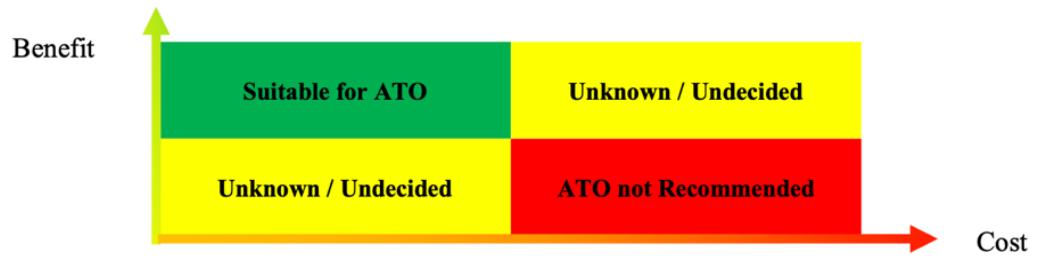

Figure. 3. Cost - Benefit Comparison Chart

\section{Case study}

8 different rail corridors in the Netherlands were selected as case studies for the application of the decision-making framework. The selected corridors are shown in table 6 .

Table 6. Case studies.

$\begin{array}{llll}\text { No. } & \text { From } & \text { To } & \text { Service } \\ \mathbf{1} & \text { Enschede } & \text { Den Haag } & \text { Mixed } \\ \mathbf{2} & \text { Utrecht Central } & \text { Uitgeest } & \text { Mixed } \\ \mathbf{3} & \text { Groningen } & \text { Zuidhorn } & \text { Regional } \\ \mathbf{4} & \text { Betuweroute } & - & \text { Freight } \\ \mathbf{5} & \text { Amsterdam Central } & \text { Utrecht Central } & \text { Intercity } \\ \mathbf{6} & \text { Rotterdam - } & \text { Den Haag } & \text { Mixed }\end{array}$




$\begin{array}{llll}\text { No. } & \text { From } & \text { To } & \text { Service } \\ 7 & \text { Arnhem - } & \text { Winterswijk } & \text { Regional } \\ 8 & \text { Nijmegen } & \text { Den Bosch } & \text { Mixed }\end{array}$

The above rail corridors were evaluated with the support of the decision-making framework for their suitability to deploy ATO.

\section{Framework results}

The main objective of this research was to develop a tool which could suggest expediency of ATO over ETCS in the heavy rail. The methodology and approach taken during this research resulted in a framework which fulfilled the objective. In this section, the results of the case studies are presented and discussed.

\subsection{Expediency of ATO for Dutch Railways}

The case study results are shown in below figures. The vertical axis represents the benefits while the horizontal one is for the costs. The legend of Figure 3 applies to Figures 4, 5 and 6. A colour coding was used to distinguish between the different services, as detailed in Table 7.

Table 7. Colour Coding for Service

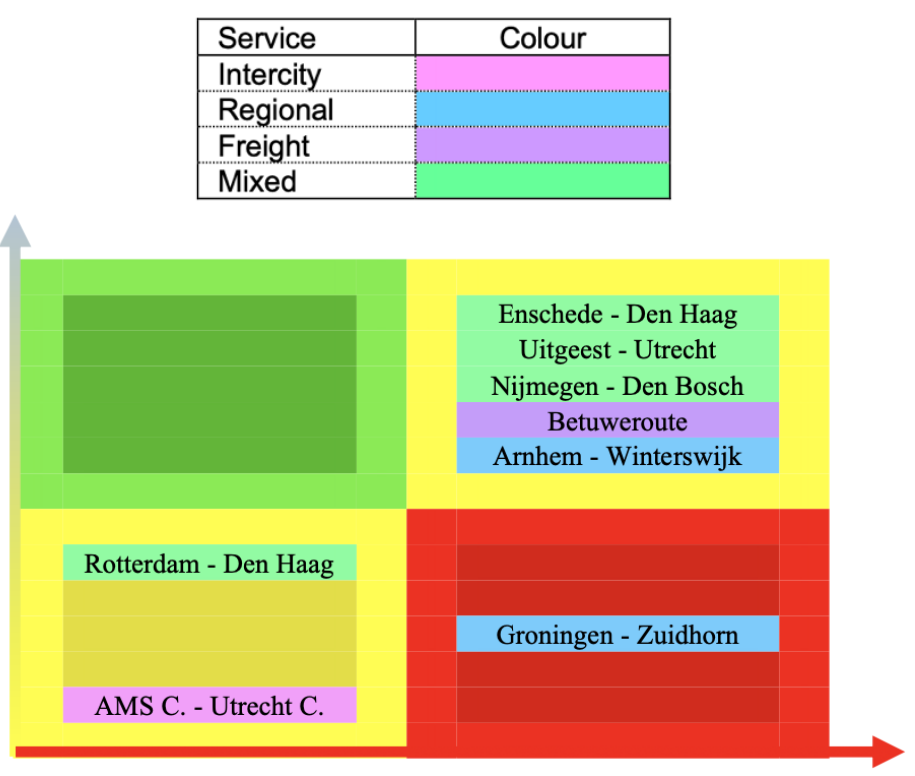

Figure. 4. Framework results for GoA 2 
In GoA 2, there is no significant gain from the corridor independent KPIs (flexibility, reputation and staff costs). The corridor dependent KPIs (punctuality and energy usage) become noticeable on corridors where the costs are also high. Therefore, there is doubt about the suitability of GoA 2 for the heavy rail.

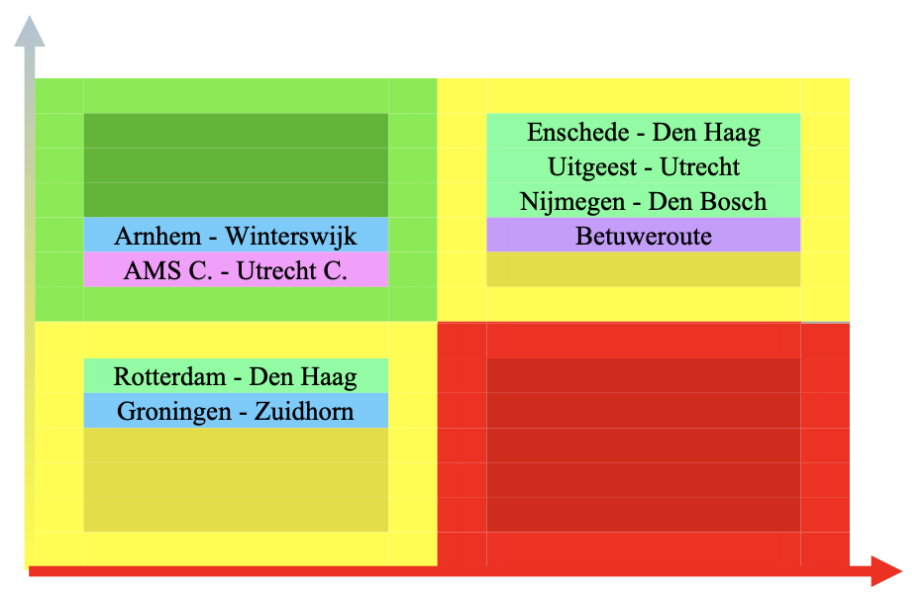

Figure. 5. Framework results for GoA 3

On corridors which are segregated, the investment cost for the on-board are not considerable and would be the same as GoA 2 as there is no requirement for obstacle detectors. For relatively short rail corridors, the investment cost for ATO trackside is also not remarkable. The investment costs for ATO are also not significant on regional corridors with light traffic. In case of GoA 3, the staff costs are partly reduced, and flexibility and reputation are gained to some extent. Two categories of corridors could be suitable for GoA main segregated corridors which are relatively short and regional corridors which include many stations. On these regional corridors, punctuality can be improved, and energy could be more efficiently used.

On the other rail corridors, there is doubt if the benefits from implementing ATO could compensate for the costs.

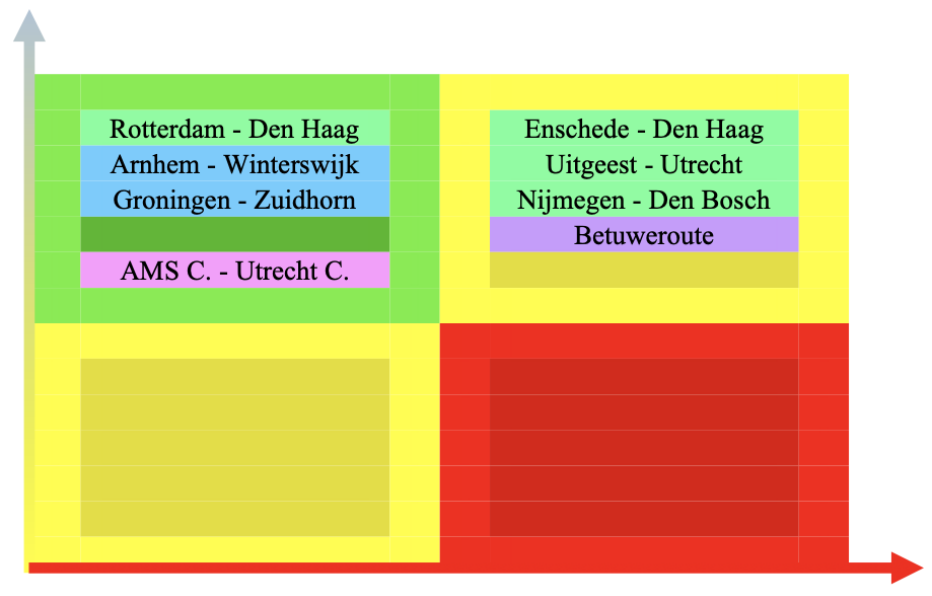

Figure. 6. Framework results for GoA 4

In GoA 4, there is an additional flexibility gain and staff costs could be further reduced. These additional gains are likely to compensate the costs in regional and relatively short main 
/ freight corridors. On the other rail corridors, there is again doubt if the benefits from implementing ATO could compensate for the costs.

\section{Discussion}

The objective of the framework was to analyse rail corridors and determine the expediency of ATO. However, rail corridors are part of the railway network. Therefore, it is important to understand the impact of ATO over ETCS on the railway network considering the suggestions given by the framework.

The current corridor segmenting in the Netherlands has resulted in dependencies between the corridors. Therefore, in case ATO is decided on a corridor (e.g. Amsterdam Central Utrecht Central), there would be transitions between manual and automated operation. These transitions could result in the following challenges:

- Information Presented on DMI

- Human Factor

- Planning and Scheduling for Train Driver

\section{Framework validation}

\subsection{Review meetings}

At the end of each stage, design review meetings were held with experts. In these review meetings, railway experts and university scholars were present. Methods and results were discussed and if approved, next stage activities were carried out.

\subsection{Applicability analysis}

In order to determine the accuracy and acceptability of the designed framework, an applicability analysis is done. The framework was applied to two currently automated urban rail systems. This was due to the similarity of the architecture and operational principles of ATO in heavy rail and the urban rail system.

The chosen corridors are Canada line, which is operating with GoA 4, and Amsterdam Noord - Zuid line that is capable of operating with GoA 4.

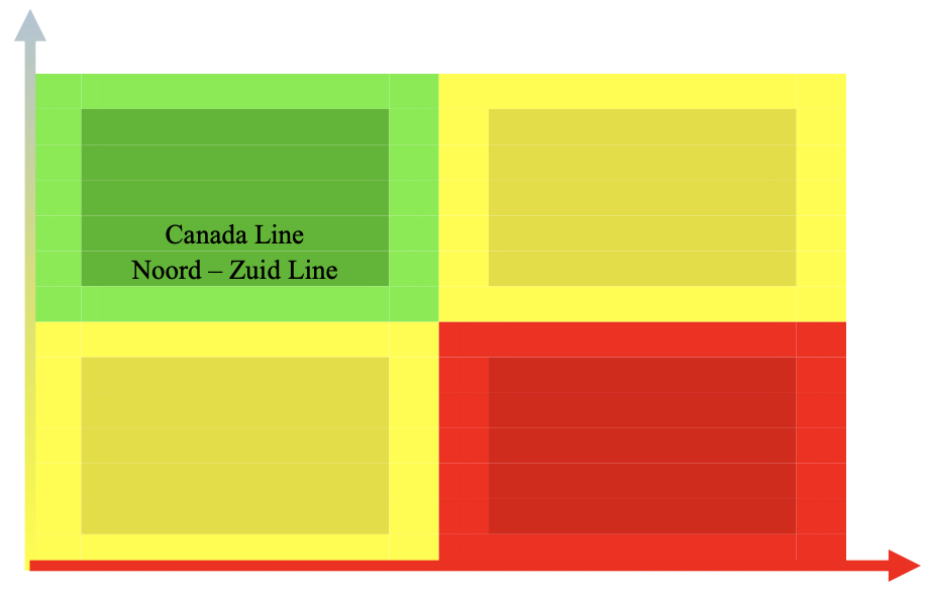

Figure. 7. Applicability results for GoA 4 
The framework supports the decisions to implement GoA 4 for Canada line and NoordZuid line. Consequently, it can be concluded that the framework returns reliable results.

\section{Recommendations}

The recommendations for future work include:

1. A return of investment analysis along with a quantitative approach is suggested for a detailed study and determining the break-even points.

2. The impact of transitions between manual and automated operation should be further studied in order to determine and manage the challenges which could occur as a result of transitions.

\section{Conclusion}

In conclusion, the main objective of this research was to develop a tool which could suggest expediency of ATO over ETCS Level 2 in the heavy rail for the Dutch railway. The methodology and approach taken during this research resulted in a framework which fulfilled the objective. The following results were obtained after applying the framework to corridors in the Dutch railway:

- The framework suggests that GoA 2 may not be suitable for the Dutch railway. However, GoA2 is an entry door towards automatic operation and ensures smooth migration towards higher GoA,

- A positive business case for a few corridors in the Netherlands could be defined for GoA3. These corridors include relatively short main corridors which are segregated and regional corridors which have many stations.

- Regional corridors and relatively short main corridors could be suitable for GoA 4.

- Corridors with dense traffic which are relatively long may not be suitable for automated operation.

However, considering the current corridor segmenting and dependencies between the corridors, additional challenges would result from implementing automation. These challenges are due to the transitions between manual and automated operation and could even limit the benefits gained from automation.

\section{Acknowledgment}

The authors very much appreciate the support of Henk Barten, Aspectmanager Toelating Veilige Integratie at NS, and Mark Van Hesse, Sr Consultant Railway Signalling \& Safety at Mott MacDonald, for their support and providing valuable insight.

The authors also thank the experts who were involved in the survey. Without their passionate participation and input, the survey could not have been successfully conducted.

\section{References}

1. https://projects.shift2rail.org/s2r_projects.aspx

2. ETCS System Description, RSSB (2010)

3. IEC, IEC 62290 - Railway applications - Urban guided transport management and command/control systems, Part 1: System principles and fundamental concepts (2014)

4. Railmap 4.0, ERTMS (2019) 
5. R. Hayes, S. Wheelwright, Restoring Our Competitive Edge: Competing Through Manufacturing (1984)

6. Department of Defence, Standard Practice System Safety (2000)

7. Official Journal of the European Union, Directive 2016/798, (2016)

8. M. Abril, F. Barber, L. Ingolotti, M.A. Salido, P. Tormos, A. Lova, An Assessment of Railway Capacity, Transportation Research Part E: Logistics and Transportation Review, 44, (2008)

9. C. Fombrun, Reputation Management: A Framework for Measurement and Valuation (2005)

10. J. Moses, Flexibility and Its Relation to Complexity and Architecture in Complex Systems Design and Management, Springer (2010)

11. A. Froger, O. Guyon, E. Pinson, A set packing approach for scheduling passenger train drivers: the French experience (2015) 


\section{Appendices}

\section{Appendices A}

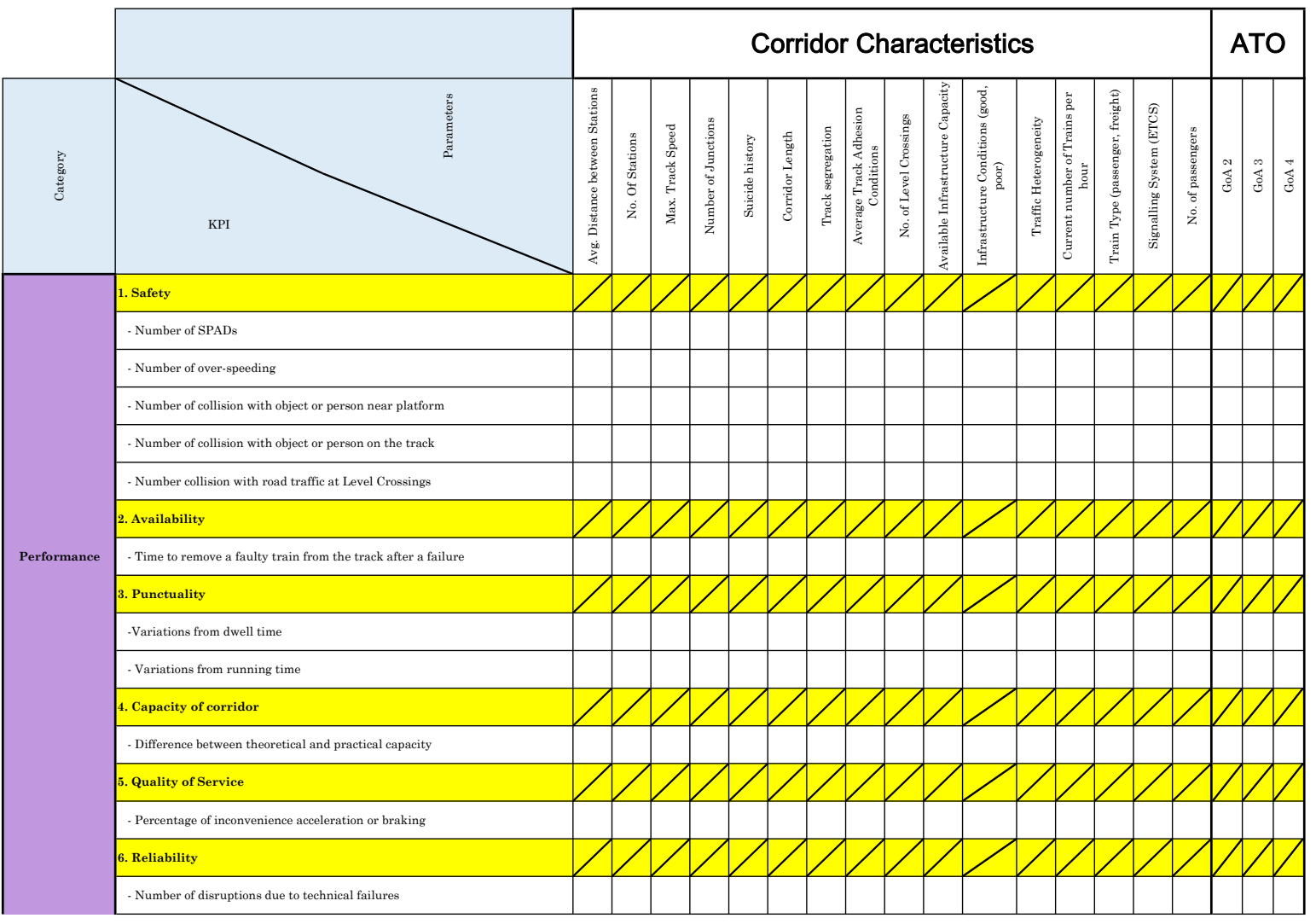




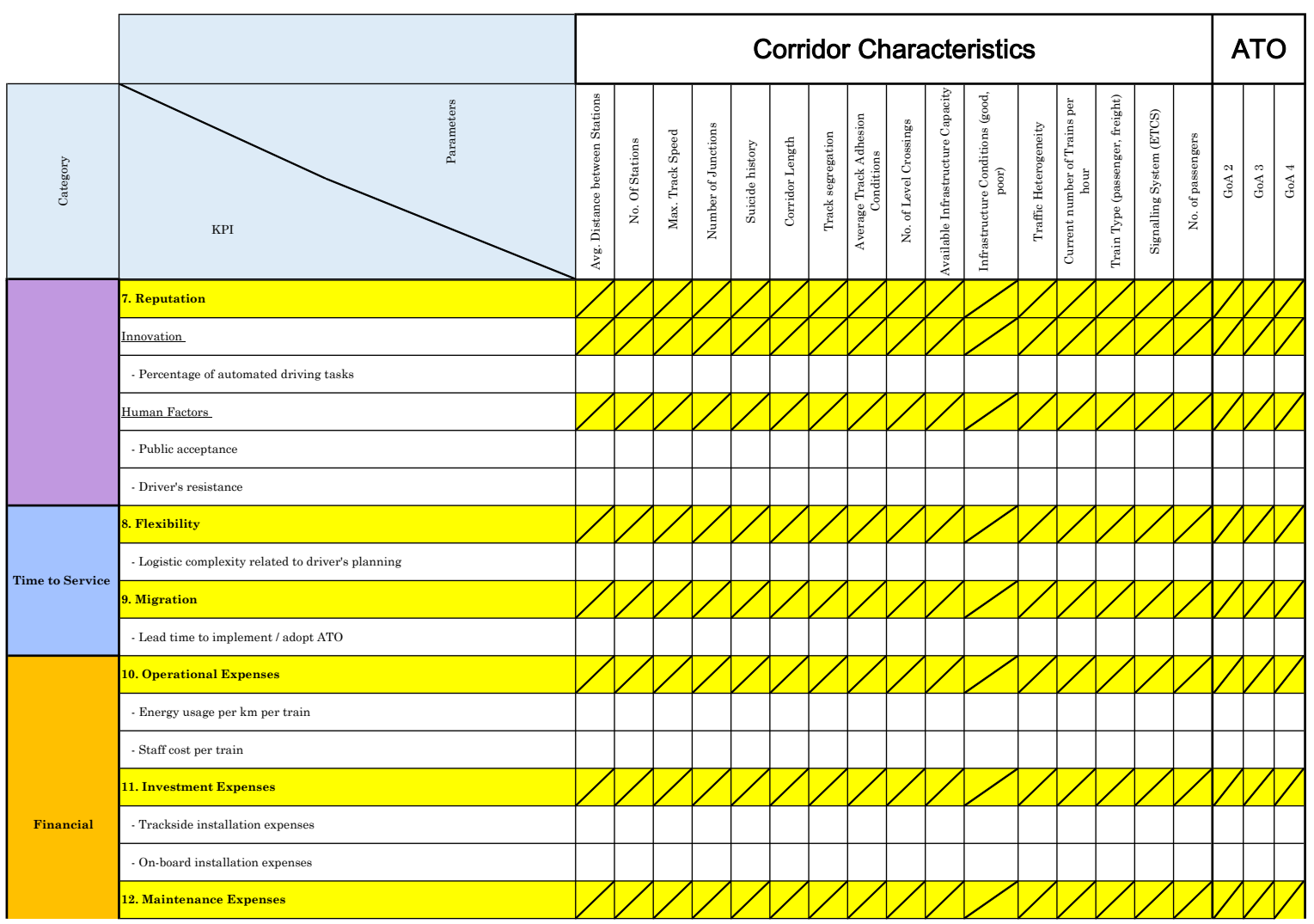




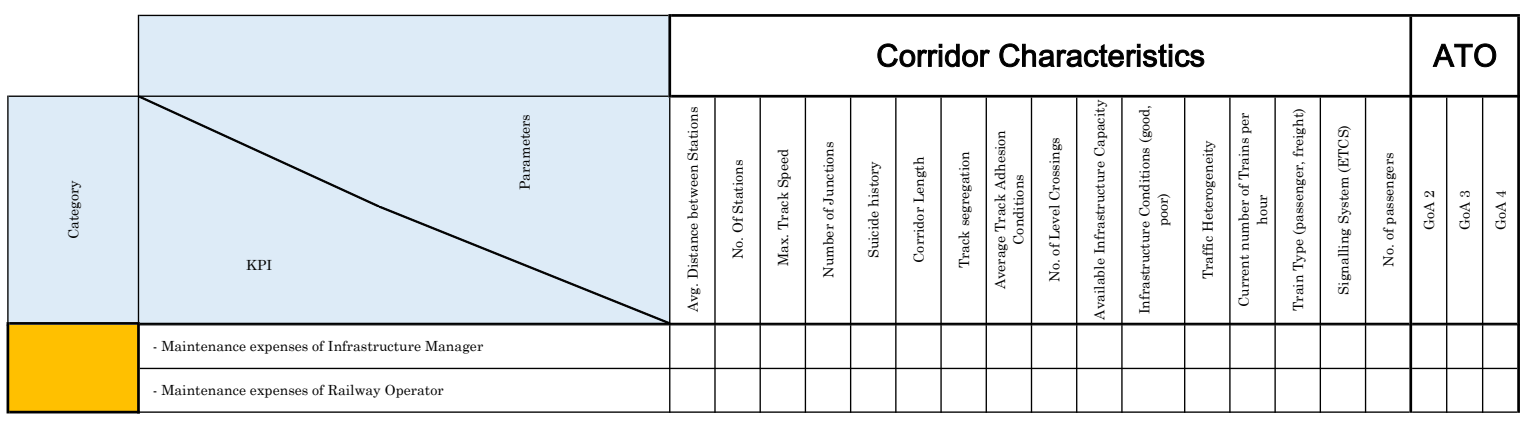

\begin{tabular}{|c|c|}
\hline \multicolumn{2}{|r|}{ Legend } \\
\hline \multicolumn{2}{|r|}{$\underline{\text { Corridor }}$} \\
\hline & No Relation \\
\hline$\bullet$ & Relation \\
\hline \multicolumn{2}{|r|}{$\underline{\mathrm{ATO}}$} \\
\hline スス & Strong Increase (more than $50 \%$ ) \\
\hline オ & Weak Increase (less than $50 \%$ ) \\
\hline$\rightarrow$ & No Change \\
\hline$?$ & Unknown \\
\hline$y$ & Weak Decrease (less than $50 \%$ ) \\
\hline$\searrow \searrow$ & Strong Decrease (more than $50 \%$ ) \\
\hline$<50 \%$ & Weak \\
\hline$>50 \%$ & Strong \\
\hline
\end{tabular}




\section{Appendix B - Survey Participants}

\begin{tabular}{lc}
\hline \multicolumn{1}{c}{ Role } & Organization \\
\hline Head of Quality Management & Railway Undertaking \\
\hline Senior Rail Manager & Consultancy Firm \\
Consultant Railway Signalling \& Safety & Consultancy Firm \\
\hline Consultant Transportation & Consultancy Firm \\
Manager systeemintegratie & Infrastructure Manager \\
\hline Programmemanager Smart \& Green & Government Official \\
Mobility and Public Transport & Railway Undertaking \\
Manager Safety & Railway Undertaking \\
\hline Programmamanager ATO & Signalling System Manufacturer \\
\hline ATO Project Managar & Infrastructure Manager \\
\hline Advisor Innovation and Development & Consultancy Firm \\
Consultant Railway Safety \& Signalling & Railway Undertaking \\
\hline Implementatie manager & Consultancy Firm \\
\hline Consultant Integration Management & Infrastructure Manager \\
\hline Project Manager for ATO & Signalling System Manufacturer \\
\hline ATO Project Managar & Consultancy Firm \\
\hline Consultant Railway Signalling \& Safety & Consultancy Firm \\
\hline Consultant Transportation & \\
\hline
\end{tabular}

